\title{
Strategi Kepala Sekolah Mengembangkan Budaya Islami Di SMP Islam Terpadu Se Kecamatan Tanayan Raya Pekanbaru
}

\author{
Tika Emilda \\ IAI Pelalawan \\ Pelalawan \\ emildatika@gmail.com
}

\section{Abstrak}

Jurnal ini bertujuan untuk mengetahui strategi-strategi yang dapat dilakukan oleh Kepala Sekolah untuk mengembangkan budaya Islami untuk Sekolah yang berciri khas Islam (Islam Terpadu). Hasil penenlitian yang dilakukan diseluruh SMP Se Kecamatan Tanayan Raya Pekanbaru hampir seluruh Kepala Sekolah sudah melaksanakan budaya Islami yang menjadi ciri khas Sekolah Islam Terpadu (IT) diantaranya: Kepala Sekolah menerapkan kebijakan untuk membiasakan diri dengan S3 (salam, Senyum dan Sapa), membiasakan berjabat tangan antara guru dengan guru dan dengan siswa, membiasakan berdoa sebelum dan sesudah pembelajaran, membaca qur'an, membiasakan shalat Dhuha Zhuhur dan Ashar berjamaah, Muhadarah. Selain kebijakan diatas Kepala Sekolah juga menerapkan metode Keteladanan, membiasakan hal-hal yang baik, menegakkan kedisiplinan, memberikan motivasi dan kerjasam denghan orang tua dalam menegakkan budaya Islami

\section{Abstract}

This journal aims to find out the strategies that can be carried out by school principals to develop Islamic culture for schools characterized by Islam (Integrated Islam). The results of 
research conducted in all SMPs in Tanayan Raya Pekanbaru District, almost all school principals have implemented Islamic culture that is the hallmark of Integrated Islamic Schools (IT) including principals implementing policies to familiarize themselves with S3 (greetings, smiles, and greetings), getting used to shaking hands between teacher and teacher and with students, getting used to praying before and after learning, reading the Qur'an, getting used to praying the Dhuha Zhuhur and Asr in the congregation, Muhadarah. In addition to the above policy the principle also applies the Exemplary method, familiarizes good things, enforces discipline, provides motivation, and cooperation with parents in upholding Islamic culture.

\section{Kata Kunci: Strategi Kepala Sekolah, Budaya Islami Keywords: Principal Strategy, Islamic Culture}

\section{A. PENDAHULUAN}

Pendidikan adalah usaha sadar yang harus dikembangkan untuk meraih tujuan pendidikan secara nasional yakni menjadikan manusia berakhlak mulia, berbudi pekerti luhur, beriman dan bertakwa serta menuntuk untuk kemandirian para siswa. Semua tujuan itu dapat terwujud apabila semua komponen bergerak berkerja sama bersinergi untuk mewujudkan tujuan pendidikan secara sempurna.

Mewujudkan tujuan pendidikan Nasional tersebut yakni beriman, bertaqwa dan berakhlak mulia Sekolah berbasis Islami merupakan wadah yang tepat dalam mewujudkan tujuan tersebut karena di Sekolah berbasis Islam terpadu dimana dididik untuk menerapkan nilai-nilai keIslaman yang terkandung dalam al-qur'an dan Sunnah Nabi Muhammad SAW. Salah satu fungsi pendidikan dalam Islam yakni membimbing, mengarahkan manusia untuk menjalankan tugasnya sebagai khalifah fil ardi yakni 
khalifah dimuka bumi yang itu semua dapat diproses melalui pendidikan yang berbasis Islam.

Sebuah lembaga pendidikan akan berkembang dengan baik jika dipimpin oleh seorang Kepala Sekolah yang baik pula. Kepala Sekolah merupakan orang yang dipercayai untuk mengelola lembaga, maka sudah seharusnya Kepala Sekolah memliki startetgi-strategi untuk digunakan dalam kepemimpinannya dalam mencapai tujuan pendidikan yang diharapkan.

Berbicara mengenai startegi Kepala Sekolah tentang menerapkan budaya Islami harus merujuk kepada Alqur'an dan hadist yang akan dijadikan sebagai pedoman dalam penerapan budaya Islami. Banyak cara yang dilakukan Kepala Sekolah diantaraya: dengan memulai dari diri sendiri dengan metode keteladanan. Kepala Sekolah memberikan contoh sikap teladan kepada bawahannya contoh yang sederhanaya adalah dengan mengucapkan salam ketika bertemu dengan guru maupun dengan siswa, secara tidak langsung bawahannya akan mengikuti kebiasaan-kebiasaan yang dilakukan oleh pimpinan. Budaya merupakan persepsi dasar atau keyakinan anggota kelompok sebuah lembaga/organisasi. ${ }^{1}$

Menciptakan budaya Islami berarti menciptakan iklim kehidupan keagamaan yang bernafaskan dari ajaran nilainilai keIslaman yang nilai tersebut diwujudkan dalam sikap hidup mereka dalam bertindak dan berperilaku. ${ }^{2}$ Salah satu yang melatar belakangi Kepala Sekolah menerapkan budaya Islami ini karena krisis moral yang terjadi di sekarang ini yang sudah melanda diseluruh lapisan masyarakat dari atas sampai kebawah maka inilah yang

1 Nurkolis, Manajemen Berbasis Sekolah, (Cet. II; Jakarta: PT. Grasindo, 2005), h. 200.

${ }^{2}$ Mulyasa, Pedoman Manajemen Berbasis, Madrasah, (Cet. II; Jakarta: Departemen Agama RI, 2005),h.32 
J-Al-Mutharahah : Vol. 17 No. 1 Januari-Juni 2020

melandasi pentingnya menerapkan budaya Islami dilingkungan Sekolah untuk membentengi diri peserta didik dan lingkungan Sekolah dari krisis moral yang berkembang saat ini.

\section{B. METODE PENELITIAN}

Pendekatan dalam penelitian ini adalah pendekatan kualitatif. Metodologi kualitatif adalah prosedur penelitian yang menghasilkan data deskriptif berupa kata-kata tertulis atau lisan dari orang-orang dan perilaku yang dapat diamati. ${ }^{3}$ Sementara itu Cresswell penelitian kualitatif didefinisikan sebagai suatu proses penelitian untuk mengetahui tentang permaslahan manusia atau sosial dengan membentuk gambaran menyeluruh dan kompleks disajikan dengan kata-kata. Teknik pengumpulan data dalam penelitian ini menggunakan teknik Observasi, wawancara dan dokumentasi. Teknik analisis data mengggunakan analisis data induktif yaitu proses menganalisis yang berangkat dari fakta-fakta khusus kemudian ditarik generalisasi yang bersifat umum.

\section{PEMBAHASAN}

\section{Strategi Kepala Sekolah}

Strategi kepemimpinan merupakan sebuah tuntutan kepada para pemimpin yang bersifat fleksibel dalam mengatasi suatu permasalahan yang tidak diharapkan kehadirannya dan tuntutan bagi mereka untuk mempunyai visi yang berpandagan jauh kedepan dalam mengatasi permsalahan yang ada4. Dengan demikian

3 Lexy . J. Moleong, Metodologi Penelitian Kualitatif Edisi Revisi. (Bandung: Remaja Rosda Karya, 2012), hal. 4

4 Tony Bush dan Marianne Coleman, Manajemen Strategi Kepemimpinan Pendidikan, terj. Fahrurrozi, (Yogyakarta: Ircisod, 2008), h. 9193. 
dapat dijabarkan strategi kepemimpinan adalah rencana yang akan dilakukan oleh pemimpin dalam mencapai visi dan misi mereka untuk kemajuan lembaga yang mereka pimpin. ${ }^{5}$

Kepala Sekolah merupakan pemimpin dalam sebuah lembaga yang dipimpin yang salah satu fungsinya mempengaruhi dan menggerakkan masyarakat Sekolah dalam mencapai tujuan pendidikan Sekolah itu sendiri, keberhasilan suatu lembaga pendidikan sangat tergantung pada kepemimpinan Kepala Sekolah maka sudah seharusnya Kepala Sekolah membawa perubahan-perubahan atau pembaharuan untuk kemajuan Sekolah yang dipimpinnya. Begitu besar peran Kepala Sekolah dalam mencapai tujuan pendidikan yang diharapkan salah satu faktor keberhasilan Kepala Sekolah dalam kepemimpinannya adalah tentang keahliannya dalam memainkan strategi , teknik dan gaya kepemimpinan. Dengan memainkan keahliannya tersebut maka tujuan pendidikan akan terwujud sebagaimana yang diharapkan.

\section{Budaya Islami di Sekolah}

Saleh Muntasir mendefinisikan budaya Islami adalah suatu keadaan yang memungkinkan setiap anggota keluarga beribadah kepada Tuhan dengan cara yang telah dijelaskan oleh agama, dengan suasana tenang, bersih, hikmat. Sarananya adalah selera religius, selera etis, estetis, kebersihan, itikad agama dan ketenangan. ${ }^{6}$ Budaya Islami lembaga pendidikan adalah suatu cara mewujudkan nilai ajaran agama sebagai budaya dalam bertingkah laku dalam organisasi yang diikuti

${ }^{5}$ Wahjosumidjo, Kepemimpinan Kepala Sekolah; Tijauan Teoritik Dan Permasalahannya, (Jakarta: PT Raja Grafindo Perkasa, 2007), h. 83.

${ }^{6}$ M. Saleh Muntasir, Mencari Evidensi Islam (Analisa Awal Sistem Filsafat, Strategi, dan Metodologi Pendidikan), (Jakarta: Rajawali, 1985), h. 120. 
steakholder Sekolah. Dengan menjadikan agama sebagai tradisi dalam sebuah lemaga pendidikan maka secara sadar maupun tidak sudah menanamkan nilai-nilai ajaran agama Islam dalam berperilaku pada sebuah lembaga pendidikan.

Budaya beragama di Sekolah merupakan cara berfikir dan cara bertindak warga Sekolah yang didasarkan atas nilai-nilai Islami (keberagaman). ${ }^{7}$ Budaya beragama di Sekolah merupakan sekumpulan nilai-nilai agama yang diterapkan di Sekolah, yang melandasi perilaku, tradisi, kebiasaan, keseharian dan simbol-simbol yang dipraktikkan oleh seluruh warga Sekolah, merupakan perilaku-perilaku atau pembiasaan-pembiasaan yang diterapkan dalam lingkungan Sekolah sebagai salah satu usaha untuk menanamkan akhlak mulia pada diri anak didik.

Budaya Islami akan menjadi ciri khas tersendiri nilai keIslaman yang terkandung di dalam lembaga pendidikan Islam merupakan modal utama untuk mewujudkan sebuah lembaga pendidikan yang unggul diera sekarang ini, adapun komponen daya tarik yang ada dalam sebuah klembaga tersebut seperti dasar pendidikan, tujuan, kurikulum, metode dan strategi harus didasarkan pada nilai moral dalam ajaran Islam. ${ }^{8}$ Hal inilah yang menjadi ciri khas yang membedakan antara organisasi yang Islami dengan yang tidak. Dapat disimpulkan bahwa budaya Islami adalah aturan hidup yang bersumber dari al-qur'an dan sunnah. Budaya ini dapat diterapkan sebagai alat pengajaran yang berbasis

${ }^{7}$ Asmaun Sahlan, Mewujudkan Budaya Religius di Sekolah (Upaya Mengembangkan PAI dan Teori ke Aksi), (Malang: UIN Maliki Press, 2010), h. 75.

${ }^{8}$ Abuddin Nata, Manajemen Pendidikan: Mengatasi Kelemahan

Pendidikan Islam di Indonesia, (Jakarta: Kencana, 2010), cet.4. h. 173. 
nilai di Sekolah, khususnya Sekolah yang bercirikan Islam. Cerminan dari nilai keislaman ini adalah tersenyum, menghargai waktu, pekerja keras, saling tolong menolong dan berkompetensi. ${ }^{9}$

\section{Strategi Mengembangkan Budaya Islami DiSekolah}

Menurut Ahmad Tafsir strategi yang dapat dilakukan diantaranya:

a. Melalui teladan

b. Membiasakan hal-hal yang baik

c. Menegakkan disiplin

d. Memberikan motivasi

e. Menciptakan suasana yang religius ${ }^{10}$

Sedangkan strategi mewujudkan budaya Islami diSekolah menuru Koentjaraningrat yaitu; tataran nilai yang dianut, tatanan praktik keseharian dan tataran simbol-simbol budaya. ${ }^{11}$

Mewujudkan tatanan nilai budaya perlu dirumuskan dan disepakati bersama apa saja yang akan diterapkan diSekolah itu yang selanjutnya membangun komitmen dan loyalitas bersama terhadap nilai budaya yang telah disepakati. Hal ini senada dengan pendapat Hicman dan Silva bahwa untuk mewujudkan budaya ada tiga langkah yang harus dilaksanakan yaitu: Commitment, competence dan consistency. ${ }^{12}$

${ }^{9}$ Didin Hafidhuddin dan Hendri Tanjung, Manajemen Syariah dalam Praktik, (Jakarta: Gema Insani Press, 2003), h. 40.

10 Ahmad Tafsir, Metodologi Pengajaran Agama Islam, (Bandung: Remaja Rosda Karya, 2004), h. 112.

11 Koentjaranindrat, "Kebudayaan, Mentalitas dan Pembangunan" dalam Muhaimin, Nuansa Baru Pendidikan Islam, (Jakarta: Raja Grafindo Persada, 2006), h. 157.

12 Hickman dan Silva, dalam Purwanto, Budaya Perusahaan, (Yogyakarta: Pustaka Pelajar, 1984), h. 67. 
Setelah tatanan nilai disepakati langkah selanjutnya adalah menerapkan tatanan nilai tersebut. Adapun konsep penerapan budaya Islami disekola meliputi
a. Penciptaan
suasana
religius
artinya
mengkondisikan Sekolah dengan tatanan nilai religius yang dapat dilakukan dengan cara sekenario penciptaan suasana religius, menyediakan tempat ibadah dilingkungan Sekolah, sinergi seluruh masayarakat Sekolah dan juga kepemimpinan Sekolah.

b. Internalisaso nilai, dilakukan dengan cara memberikan pemahaman kepada siswa tentang tanggung jawab manusia sebagai khalifah dimuka bumi yang harus arif dan bijaksana

c. Keteladanan, anak dalam perkembangannya membutuh sosok teladan dan ini hanya akan diperoleh dari para pemimpin dan guru sebagai teladan bagi para siswa, maka sudah selayaknya guru dan Kepala Sekolah harus membrikan contoh perilaku yang baik agar anak didik dapat meniru contoh tersbut.

d. Pembiasaan, Banyak hal bentuk pengamalan nilainilai religius yang bisa dilakukan di Sekolah seperti ; saling mengucapkan salam, pembisaan menjaga hijab antara laki-laki dan perempuan (misal; lakilaki hanya bisa berjabat tangan siswa laki-laki dan guru laki-laki, begitu juga sebaliknya.), pembisaan berdoa, sholat dhuha, dhuhur secara berjamaah, mewajibkan siswa dan siswi menutup aurat, hafalan surat-surat pendek dan pilihan dan lain sebagainya. 


\section{Hasil Penelitian}

SMP Islam Terpadu adalah Sekolah Menengah Pertama yang mengkolaborasikan antara kurikulum nasional dengan kurikulum pesantren Sekolah IT merupakan rumpun dari JSIT yang merupakan lembaga masyarakat yang berkecimpung pada dunia pendidikan, bersifat terbuka dalam arti bersedia diajak untuk bekerja sama dengan pihak lain dalam hal kebaikan dan kemaslahatan tidak untuk bekerjasama dalam hal kejelekan

Mengukur keberhasilan metode pembudayaan adalah dengan melihat perilaku sehari-hari. Sehingga implementasi yang telah dilakukan berdaya guna. Untuk mengaplikasikan budaya Islami tidak bisa berjalan sendiri hartus kerja sama dengan organisasi untuk menerapkan budaya itu, sehingga hal-hal dalam usaha menciptakan tujuan pendidikan dapat berlangsung dengan baik.

Berdasarkan hasil penelitian tentang strategi Kepala Sekolah dalam mengembangkan budaya Islami yang penulis lakukan diseluruh SMP IT se Kecamatan Tanayan Raya Pekanbaru dapat ditarik kesimpulan bahwa seluruh Kepala Sekolah memiliki Strategi dalam mengembangkan budaya Islami. Hal ini terlihat dari perencanaan dalam kegiatan Islami yang dilanjutkan dengan pelaksanaannya serta evaluasi pelaksanaan tersebut menjadi lebih baik lagi.

Untuk mendukung hasil penelitian itu penulis menemukan temuan penelitian diantaranya

1. Kepala Sekolah memberikan contoh atau menjadi teladan bagi para masyarakat Sekolah ini terbukti dengan temuan peneliti terlihat dari setiap Kepala Sekolah yang berusaha menjaga sikap, perkataan dan menjadi menjadi teladan bagi para guru seta ikut berpartisipasi dalam setiap kegiatan Islami yang telah dilaksanakan. Hal itu juga diperkuat dengan perkataan dari guru Pendidikan Agama 
Islam yang berada di Sekolah tersebut yang juga mengungkapkan hal yang demikian.

2. Menerapkan kedisiplinan ini terbukti Setiap Kepala Sekolah telah menerapkan kedisiplinan dalam lembaga pendidikan yang mereka pimpin, baik disiplin dalam segi waktu, kerapian pakaian, beribadah dan kebersihan. Semua kedisiplinan tersebut telah dijalankan dengan sebaik-baiknya walau pun setiap Sekolah memili batas tertentu dalam kedisiplinan yang mereka terapkan.

3. Memberikan motivasi, dalam temuan peneliti juga mendapati Kepala Sekolah selalu memberikan motivasi kepada guru, karyawan dan siswa dalam usaha mengembangkan budaya Islami, bahkan sebagian Kepala Sekolah ada yang memberikan hadiah bagi para penunjang peningkatan budaya Islami di Sekolah mereka

4. Menciptakan suasana budaya Islami, berdasarkan temuan peneliti dilapangan bahwa hampir seluruh Kepala Sekolah menerapkan budaya ini dengan bukti seluruh guru siswa dan karyawan memakai busana yang syar'i dengan menutu aurat, menjaga jarak/memisahkan tempat duduk guru laki-laki dan perempuan, terdengar laantunan ayat suci alqur'an sebelum pelajaran dimulai, sikap sopan dan santun, dan pelayanan yang baik kepada para tamu dari luar Sekolah.

5. Di dalam penelitian ini peneliti juga melihat para Kepala Sekolah yang telah menerapkan budaya Islami di Sekolah. Terlihat dari cara Kepala Sekolah yang selalu menerapkan kedisiplinan, memberikan pemahaman ke Islaman, kegiatan-kegiatan Islami, bahkan ada yang menerapkan sistem pesantren. Selain itu meskipun belum ada peraturan khusus 
bagi orang tua siswa, tetapi Kepala Sekolah berusaha agar orang tua juga ikut berpartisipasi dalam mengembangkan budaya Islami, terlihat dalam upaya Kepala Sekolah mengadakan pertemuan dan mengharapkan agar orang tua lebih memahami tentang budaya Islami dan pengaplikasiannya di rumah sehingga anak tidak hanya terbiasa berbuda Islami di Sekolah tetapi juga di luar Sekolah.

\section{E. KESIMPULAN}

Secara umum strategi Kepala Sekolah SMP IT se Kecamatan Tenayan Raya Pekanbaru yaitu menerapkan kegiatan-kegiatan Islami dalam seruluh lingkungan Sekolah serta mengharapkan kerjasama dari orang tua agar ikut membiasakan budaya Islami di rumah. Memberikan pengajar-pengajar terbaik yang mempunyai kualitas dan berakhlak mulia agar membentuk karakter siswa yang berbuda Islami. Meskipun demikian, salah satu Sekolah bukan hanya Kepala Sekolah yang menjadi pemimpin dalam membina budaya Islami, tetapi ada penanggung jawab tersendiri yang memegang peran dalam mengembangkan budaya Islami tersebut. Menjalankan peraturan dan kegiatan yang bersifat Islami. Ada beberapa kegiatan Islami yang di wajibkan bagi siswa agar bisa terbiasa untuk berbudaya Islami baik dalam lingkungan Sekolah mau pun di luar Sekolah. Kepala Sekolah selalu mengevaluasi setiap kegiatan dan program Islami yang telah dilaksanakan, memperbaiki kesalahan dan kekurangan dari program yang telah dilaksanakan 
J-Al-Mutharahah : Vol. 17 No. 1 Januari-Juni 2020

\section{REFERENSI}

Ahmad Tafsir, Metodologi Pengajaran Agama Islam, (Bandung:

Remaja Rosda Karya, 2004),

Asmaun Sahlan, Mewujudkan Budaya Religius di Sekolah (Upaya Mengembangkan PAI dan Teori ke Aksi), (Malang: UIN Maliki Press, 2010)

Abuddin Nata, Manajemen Pendidikan: Mengatasi Kelemahan Pendidikan Islam di Indonesia, (Jakarta: Kencana, 2010), cet. 4 .

Didin Hafidhuddin dan Hendri Tanjung, Manajemen Syariah dalam Praktik, (Jakarta: Gema Insani Press, 2003)

Hickman dan Silva, dalam Purwanto, Budaya Perusahaan, (Yogyakarta: Pustaka Pelajar, 1984).

Koentjaranindrat, "Kebudayaan, Mentalitas dan Pembangunan" dalam Muhaimin, Nuansa Baru Pendidikan Islam, (Jakarta: Raja Grafindo Persada, 2006)

Lexy . J. Moleong, Metodologi Penelitian Kualitatif Edisi Revisi. (Bandung: Remaja Rosda Karya, 2012),

Mulyasa, Pedoman Manajemen Berbasis, Madrasah, (Cet. II; Jakarta: Departemen Agama RI, 2005)

M. Saleh Muntasir, Mencari Evidensi Islam (Analisa Awal Sistem Filsafat, Strategi, dan Metodologi Pendidikan), (Jakarta: Rajawali, 1985)

Nurkolis, Manajemen Berbasis Sekolah, (Cet. II; Jakarta: PT. Grasindo, 2005)

Tony Bush dan Marianne Coleman, Manajemen Strategi Kepemimpinan Pendidikan, terj. Fahrurrozi, (Yogyakarta: Ircisod, 2008)

Wahjosumidjo, Kepemimpinan Kepala Sekolah; Tijauan Teoritik Dan Permasalahannya, (Jakarta: PT Raja Grafindo Perkasa, 2007) 